\title{
ДИФФУЗИОННЫЕ ПОГРАНИЧНЫЕ СЛОИ В РАСТВОРЕ НА ГРАНИЦЕ С СУЛЬФОКАТИОНООБМЕННОЙ МЕМБРАНОЙ ПОСЛЕ ТЕМПЕРАТУРНОЙ МОДИФИКАЦИИ
}

\author{
() 2017 Э. М. Акберова \\ Воронежский государственный университет, Университетская пл., 1, 394018 Воронеж, Россия \\ e-mail: elmara_09@inbox.ru
}

Поступила в редакцию 19.06.2017 г.

\begin{abstract}
Аннотация. Методом лазерной интерферометрии измерены концентрационные профили и определены размеры диффузионных пограничных слоев в растворе на межфазной границе с сульфокатионообменной мембраной МК-40 после химического кондиционирования и температурного воздействия. Установлено, что при плотностях тока, превышающих предельные диффузионные, такие свойства поверхности мембран, как электрическая и геометрическая неоднородность, определяют интенсивность электроконвективного перемешивания раствора на межфазной границе и параметры диффузионных слоев.
\end{abstract}

Ключевые слова: гетерогенная сульфокатионообменная мембрана, концентрационный профиль, диффузионный пограничный слой, температурная модификация.

\section{ВВЕДЕНИЕ}

В настоящее время интенсификация электромембранных методов очистки и разделения растворов ориентируется на проведение электродиализа при сверхпредельных токовых режимах и разработку новых мембран с оптимизированной морфологией поверхности. Использование средних величин для количественного описания массопереноса в электромембранных системах является недостаточным в связи с неоднородностью распределения в них концентраций. Применение метода лазерной интерферометрии позволяет измерить локальные концентрации [1-3] и визуализировать процесс возникновения и развития диффузионных слоев [3-6] в растворе около поверхности ионообменной мембраны в широком диапазоне плотностей тока.

Одним из главных факторов, определяющих поведение ионообменных мембран при сверхпредельных плотностях тока, являются свойства поверхности. В частности, электрическая неоднородность поверхности мембран способствует возникновению и развитию электроконвективных вихрей возле их поверхности [7-12]. Известно, что длительное воздействие тока и повышенных температур на гетерогенные ионообменные мембраны приводит к необратимым изменениям структуры, взаимосвязанных с транспортными свойствами [13-23].
Цель настоящей работы - лазерно-интерферометрическое измерение концентрационных профилей и параметров диффузионных пограничных слоев в растворе на межфазной границе с гетерогенными сульфокатионообменными мембранами после температурного воздействия.

\section{ЭКСПЕРИМЕНТАЛЬНАЯ ЧАСТЬ}

Объектом исследования была выбрана серийно выпускаемая в промышленном масштабе (OOO «Щекиноазот», Россия) гетерогенная катионообменная мембрана МК-40, являющаяся композитом сульфокатионообменника КУ-2 с полиэтиленом и армирующими волокнами из капрона. После химического кондиционирования образцы мембран термостатировали при температуре $100{ }^{\circ} \mathrm{C}$ в дистиллированной воде в течение 50 ч.

Эксперименты по изучению формирования и развития концентрационных полей на межфазной границе при интенсивных токовых режимах были выполнены в семисекционной электродиализной ячейке с чередующимися катионообменными и анионообменными мембранами. Исследуемый мембранный канал состоял из однотипных катионообменных мембран МК-40. Высота мембранного канала $L$ составляла $4.1 \cdot 10^{-2} \mathrm{M}$, ширина $1.8 \cdot 10^{-2} \mathrm{M}$, межмембранное расстояние $h=2.0 \cdot 10^{-3}$ м. Раствор 0.02 М хлорида натрия в исследуемую секцию подавался со скоростью $1.3 \cdot 10^{-3} \mathrm{M}(\mathrm{Re}=2.6)$. Электро- 
диализ был проведен в гальваностатическом режиме при горизонтальной ориентации электродиализатора в гравитационном поле (устойчивая концентрационно-температурная стратификация).

Для визуализации процессов переноса на границе мембрана-раствор использовали установку по схеме Маха-Цендера. Схема, методы получения и декодирования интерферограмм описаны в $[3,24]$. Интерферограммы снимались на координате по направлению подачи раствора $y=0.64 \mathrm{~L}$. В качестве общей толщины диффузионного слоя $\delta_{\text {tot }}$ принималось расстояние от границы раздела до точки в растворе с концентрацией равной 0.99 от концентрации за его пределами (рис. $1 a$ ). Толщина диффузионного слоя Нернста $\delta_{\mathrm{N}}$ определялась как расстояние от межфазной границы до точки пересечения касательных к концентрационному профилю на границе раздела фаз и в глубине раствора. При сверхпредельных токовых режимах толщина диффузионного слоя Нернста $\delta_{\mathrm{N}}$ была, согласно [6, 25], получена пересечением касательных к профилю концентрации, проведенных на границе области конвективной нестабильности $d$ и зоны устойчивого концентрационного распределения в глубине раствора (рис. $1 b$ ). Размер области конвективной нестабильности $d$ определялся как расстояние от поверхности мембраны

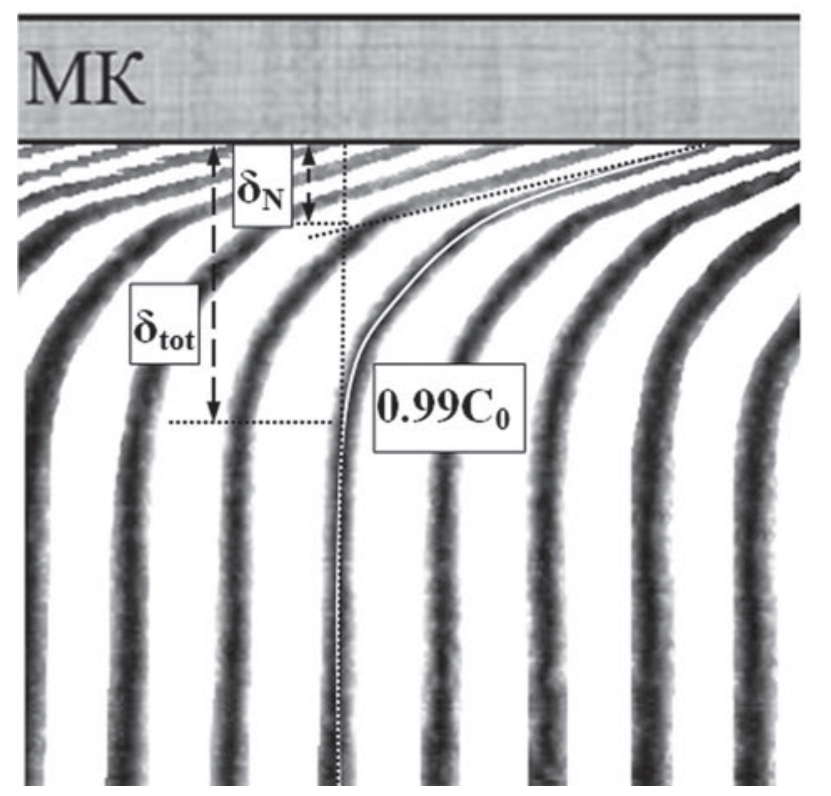

a до точки в растворе, на котором интерференционная полоса и, соответственно, концентрационный профиль имели нестационарный, колебательный характер [26].

Предварительно методом вольтамперных кривых были измерены предельные диффузионные плотности тока в $0.02 \mathrm{M}$ растворе хлорида натрия, которые составили для кондиционированного образца мембраны МК-40 1.47 мА/см², для ее термомодифицированного образца -1.70 мА/см².

\section{РЕЗУЛЬТАТЫ И ИХ ОБСУЖДЕНИЕ}

На рис. 2 представлены концентрационные профили в растворе хлорида натрия на границе с катионообменной мембраной до и после температурного воздействия. Установлена зависимость структуры диффузионных пограничных слоев от степени поляризации электромембранной системы. При токах, не превышающих предельную диффузионную величину $i_{\text {lim }}$, выявлен стационарный характер концентрационного распределения. Максимальный градиент концентрации, установленный на границе мембрана-раствор, постепенно уменьшается с увеличением расстояния от мембраны вглубь раствора. При плотности тока выше предельной диффузионной величины визуализировано возникновение электроконвективной нестабильности, за-

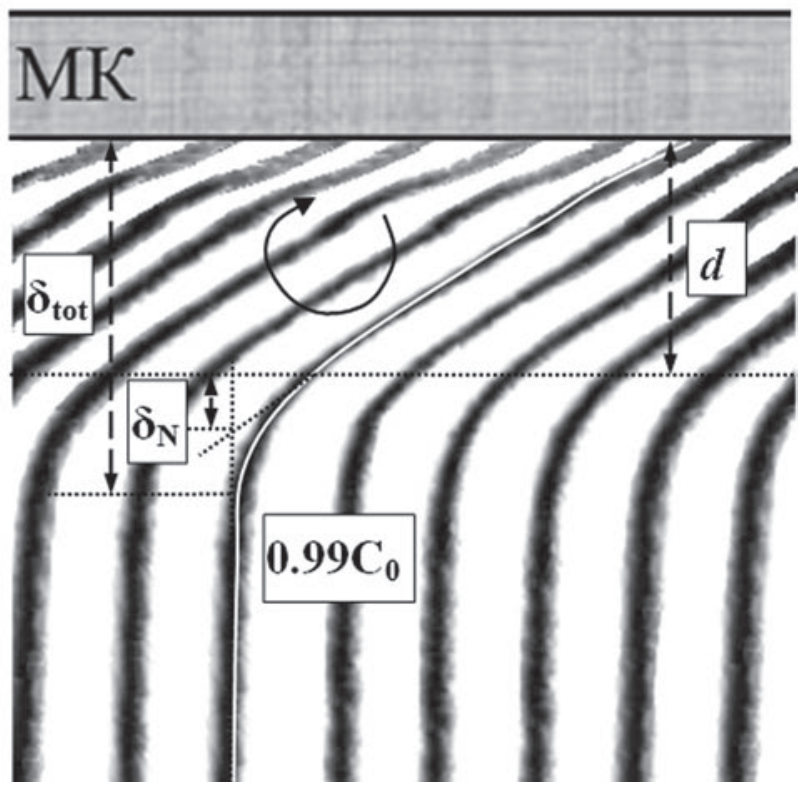

$b$

Рис. 1. Интерферограммы раствора на границе с катионообменной мембраной МК-40 (МК) при устойчивой стратификации системы и кратности превышения предельной плотности тока $i / i_{\lim }: 1.0(a)$ и $2.7(b) . C_{0}(\mathrm{NaCl})=2.0 \cdot 10^{-2} \mathrm{M}$, $V=1.3 \cdot 10^{-3} \mathrm{M} / \mathrm{c}(\operatorname{Re}=2.6), h=2.0 \cdot 10^{-3} \mathrm{M}, y=2.6 \cdot 10^{-2} \mathrm{M}(0.64 \mathrm{~L})$

[Fig. 1. Interferograms of the solution at the boundary with the MK-40 cation-exchange membrane (MK) under stable stratification of the system and current densities exceeding the limiting current density by $1.0(a)$ and $2.7(b)$ times. $\left.C_{0}(\mathrm{NaCl})=2.0 \cdot 10^{-2} \mathrm{M}, V=1.3 \cdot 10^{-3} \mathrm{~m} / \mathrm{s}(\mathrm{Re}=2.6), h=2.0 \cdot 10^{-3} \mathrm{~m}, y=2.6 \cdot 10^{-2} \mathrm{~m}(0.64 \mathrm{~L})\right]$ 
ключающееся в появлении осцилляций концентрационного профиля.

Сравнение концентрационных профилей в растворе у кондиционированной мембраны МК-40 и ее термомодифицированного образца свидетельствует о более развитой электроконвективной нестабильности на границе с мембраной после длительного воздействия повышенных температур. При превышении предельной диффузионной плотности тока в два раза электроконвективные течения, формирующиеся вблизи поверхности сульфокатионообменной мембраны после термообработки, способствуют интенсивному перемешиванию раствора, что приводит к снижению градиента концентрации в зоне вихря и уменьшению диффузионного вклада в массоперенос (рис. 2b).

На рис. 3 представлены экспериментально полученные зависимости общей $\left(\delta_{\text {tot }}\right)$ и диффузионного слоя Нернста $\left(\delta_{\mathrm{N}}\right)$ толщин, размера области конвективной нестабильности $(d)$ от безразмерной плотности тока.

При токах меньше предельных диффузионных величин установлен рост общей толщины диффузионного слоя, который обусловлен увеличением

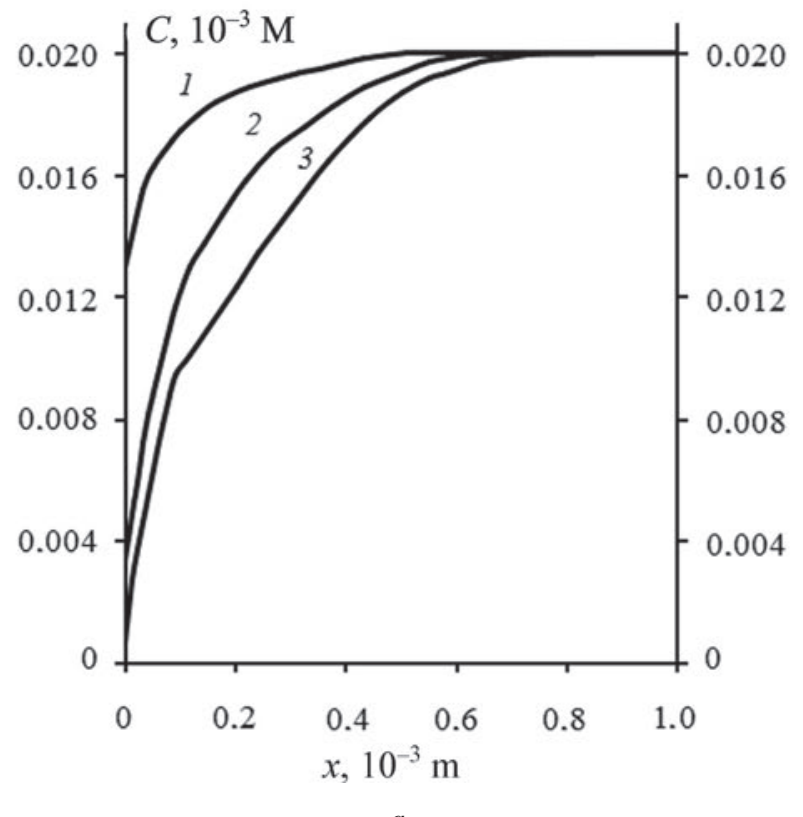

размера области концентрационных изменений в растворе на границе с мембраной, вызванного протеканием электрического тока. При $i>i_{\text {lim }}$ с ростом плотности тока экспериментально обнаружено возникновение области конвективной нестабильности раствора у поверхности мембраны, увеличение ее размеров и общей толщины $\delta_{\text {tot }}$, но уменьшение толщины диффузионного слоя Нернста $\delta_{\mathrm{N}}$. Когда размеры области конвективной нестабильности соответствуют общей толщине пограничного слоя, исчезает зона устойчивого концентрационного распределения и происходит полное разрушение диффузионного слоя. После температурного воздействия уменьшение толщины, а затем разрушение диффузионного слоя зафиксировано при степени поляризации мембраны в полтора раза меньшей по сравнению с кондиционированной мембраной. Данный факт обусловлен изменением морфологии и микрорельефа поверхности мембраны после температурного воздействия [19-23, 27, 28]. После термообработки установлено изменение доли и линейных размеров ионообменных участков до 20 \%, свидетельствующее о термохимической деструкции ионообменника $[19,20]$. В результате

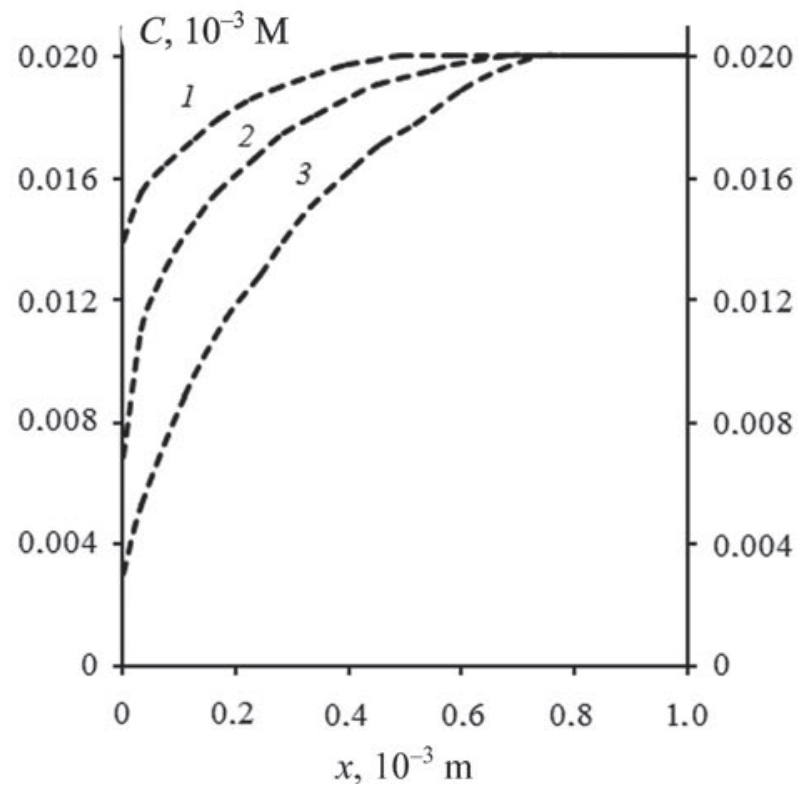

$b$

Рис. 2. Концентрационные профили в растворе $\mathrm{NaCl}$ на границе с мембраной $\mathrm{MK-40} \mathrm{при} \mathrm{устойчивой} \mathrm{стратифи-}$ кации системы и кратности превышения предельной плотности тока $i / i_{\text {lim }}: 0.5(1), 1.0$ (2) и $2.0(3) ; C_{0}(\mathrm{NaCl})=2.0 \cdot 10^{-2} \mathrm{M}$, $V=1.3 \cdot 10^{-3}$ м/с $(\operatorname{Re}=2.6), h=2.0 \cdot 10^{-3}$ м, $y=2.6 \cdot 10^{-2}$ м $(0.64 \mathrm{~L})$. Образцы мембраны: после кондиционирования $(a)$ и нагревания в воде при $100{ }^{\circ} \mathrm{C}$ в течение 50 ч $(b)$

[Fig. 2. Concentration profiles inthe $\mathrm{NaCl}$ solution at the boundary with the MK-40 cation-exchange membrane under stable stratification of the system and current densities exceeding the limiting current density by 0.5 (1), 1.0 (2) and 2.0 (3) times; $C_{0}(\mathrm{NaCl})=2.0 \cdot 10^{-2} \mathrm{M}, V=1.3 \cdot 10^{-3} \mathrm{~m} / \mathrm{s}(\mathrm{Re}=2.6), h=2.0 \cdot 10^{-3} \mathrm{~m}, y=2.6 \cdot 10^{-2} \mathrm{~m}(0.64 \mathrm{~L})$. The membrane samples: after conditioning $(a)$ and heating in water at $100{ }^{\circ} \mathrm{C}$ for $\left.50 \mathrm{~h}(b)\right]$ 

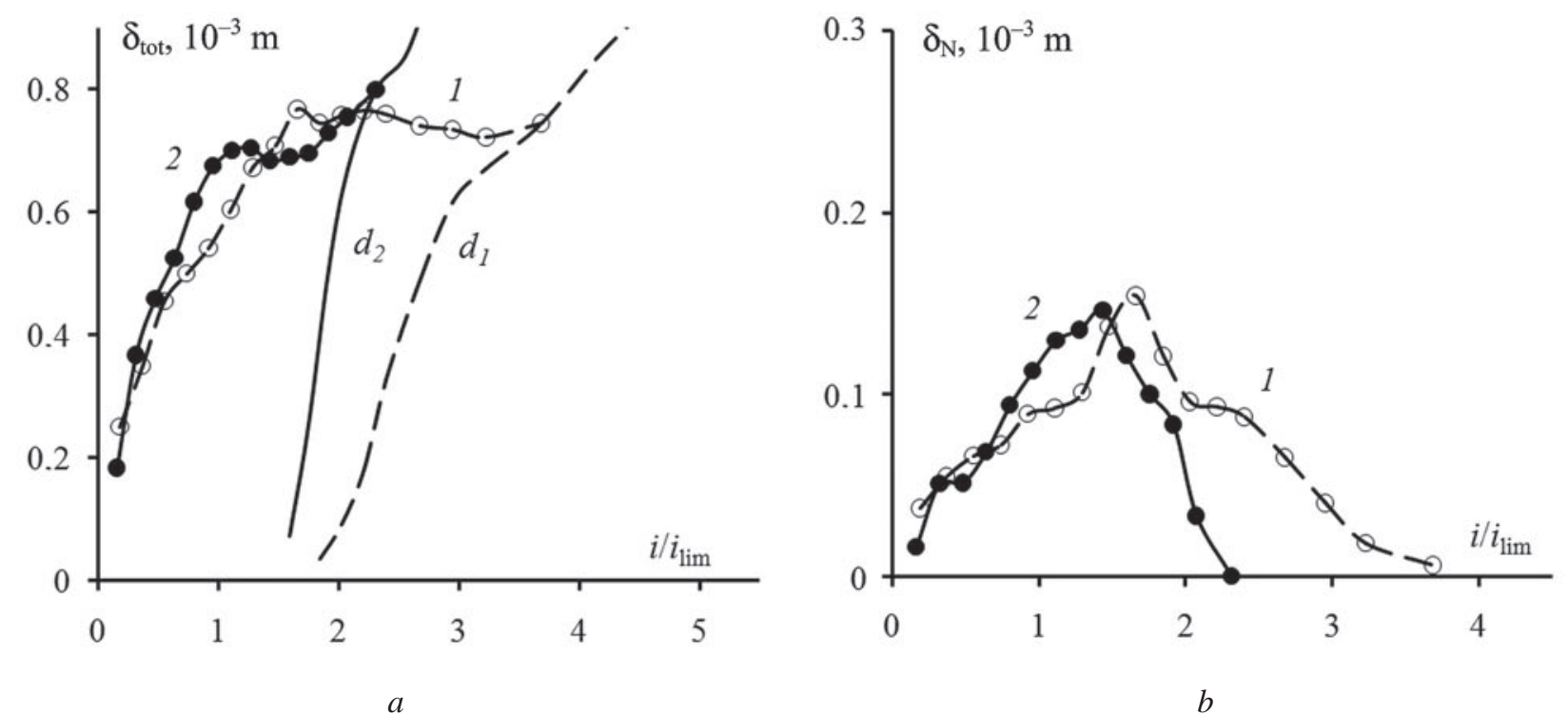

Рис. 3. Зависимость общей $(a)$ и эффективной $(b)$ толщин диффузионного слоя и размера области конвективной нестабильности $(d)$ в растворе на границе с катионообменной мембраной МК-40 после кондиционирования (1) и нагревания в воде при $100{ }^{\circ} \mathrm{C}$ в течение 50 ч (2): $C_{0}(\mathrm{NaCl})=2.0 \cdot 10^{-2} \mathrm{M}, V=1.3 \cdot 10^{-3} \mathrm{M} / \mathrm{c}(\mathrm{Re}=2.6), h=2.0 \cdot 10^{-3} \mathrm{M}$, $y=2.6 \cdot 10^{-2} \mathrm{M}(0.64 \mathrm{~L})$

[Fig. 3.The dependence of the total $(a)$ and effective $(b)$ thicknesses of the diffusion layer and the size of the convective instability region $(d)$ inthe solution at the boundary with the MK-40 cation-exchange membrane after conditioning (1) and heating in water at $100^{\circ} \mathrm{C}$ for $50 \mathrm{~h}(2): C_{0}(\mathrm{NaCl})=2.0 \cdot 10^{-2} \mathrm{M}, V=1.3 \cdot 10^{-3} \mathrm{~m} / \mathrm{s}(\operatorname{Re}=2.6), h=2.0 \cdot 10^{-3} \mathrm{~m}, y=2.6 \cdot 10^{-2} \mathrm{~m}$ $(0.64 \mathrm{~L})]$

количественной оценки порового состава набухших образцов гетерогенных ионообменных мембран выявлен рост поверхностной пористости в три раза. Для образца мембраны МК-40 после термообработки при $100{ }^{\circ} \mathrm{C}$ установлен более выраженный рельеф поверхности: размах высот и средняя арифметическая шероховатость увеличились более чем в два раза, отдельные макронеоднородности рельефа имели размах высот 1-2 мкм [28].

\section{ЗАКЛЮЧЕНИЕ}

Методом лазерной интерферометрии измерены концентрационные профили в растворе хлорида натрия на границе с сульфокатионообменной мембраной МК-40 после химического кондиционирования и температурного воздействия. Показано, что при плотностях тока, превышающих предельные диффузионные величины, концентрационные профили превращаются из стационарных в нестационарные вследствие возникающей в растворе на межфазной границе электроконвективной нестабильности. Установлено, что изменения морфологии и микрорельефа поверхности мембраны после термообработки определяют интенсивность электроконвекции и параметры диффузионных слоев при сверхпредельных плотностях тока.
Работа выполнена при финансовой поддержке гранта РФФИ (проект № 16-38-00572мол_а).

\section{СПИСОК ЛИТЕРАТУРЫ}

1. Шапошник В. А., Васильева В. И., Решетникова Е. В. // Электрохимия. 2000, т. 36, № 7, с. 872-877.

2. Васильева В. И., Шапошник В. А., Заболоцкий В. И., Лебедев К. А., Петруня И. П. // Сорбиионные и хроматографические проиессы, 2005, т. 5, № 4, c. $545-560$.

3. Vasil'eva V. I., Shaposhnik V. A., Grigorchuk O. V., Petrunya I. P. // Desalination, 2006, vol. 192, № 1-3, pp. 408-414.

4. Шапошник В. А., Васильева В. И., Григорчук О. В. // Электрохимия, 2006, т. 42, № 11, с. 13401345.

5. Васильева В. И., Григорчук О. В., Ботова Т. С., Заболоцкий В. И., Лебедев К. А. // Сорбиионные и хроматографические проиессы, 2008, т. 8, № 3, с. 359-379.

6. Nikonenko V. V., Vasil'eva V. I., Akberova E. M., Uzdenova A. M., Urtenov M. K., Kovalenko A. V., Pismenskaya N. P., Mareev S. A., Pourcelly G. // Advances in Colloid and Interface Science, 2016, vol. 235, pp. 233-246.

7. Rubinstein I., Zaltsman B. // Phys. Rev. E. 2000, part A, vol. 62, № 2,pp. 2238-2251.

8. Пивоваров Н. Я., Гребень В. П., Кустов В. Н., Голиков А. П., Родзик И. Г. // Электрохимия, 2001, т. 37, № 8, с. 941-952. 
9. Письменская Н. Д., Никоненко В. В., Мельник Н. А., Пурселли Ж., Ларше К. // Электрохимия, 2012, т. 48, № 6, с. 677-697.

10. Заболоцкий В. И., Никоненко В. В., Уртенов М. Х., Лебедев К. А., Бугаков В. В. // Электрохимия, 2012, т. 48, № 7, с. 766-777.

11. Васильева В. И., Жильцова А. В., Акберова Э. М., Фатаева А. И. // Конденсированные среды и межфазные границь, 2014, т. 16, № 3, с. 257-261.

12. Княгиничева Е. В., Белашова Е. Д., Сарапулова В. В., Письменская Н. Д. // Конденсированные среды и межфазные гранииьы, 2014, т. 16, № 3, с. 282-287.

13. Салдадзе Г. К. Ионселективные мембраны и электромембранные прочессы. М.:НИИТЭХим, 1986, c. $18-24$.

14. Березина Н. П., Ивина О. П., Рубинина Д. В. Диагностика ионообменных мембран после реального электродиализа. Краснодар, Кубанский государственный университет, 1990, 11 с.

15. Салдадзе К. М., Климова 3. В., Титова Н. А., Базикова Г. Д. Ионообменные мембраны в электродиализе. Ленинград, Химия, 1970, с. 65-75.

16. Васильева В. И., Битюцкая Л. А., Зайченко Н. А., Гречкина М. В., Ботова Т. С., Агапов Б. Л. // Сорбциионные и хроматографические процессы, 2008, т. 8, № 2, c. $260-271$.

17. Dammak L., Larchet C., Grande D. // Separation and Purification Technology, 2009, vol. 69, № 1, pp. 4347.

18. Письменская Н. Д., Никоненко В. В., Мельник Н. А., Шевцова К. А. // Мембраны и мембранные технологии, 2011, т. 1, № 3, с. 201-212.

19. Васильева В. И., Акберова Э. М., Жильцо- ва А. В., Черных Е. И., Сирота Е. А., Агапов Б. Л. // Поверхность. Рентгеновские, синхротронные и нейтронные исследования, 2013, № 9, с. 27-34.

20. Васильева В. И., Письменская Н. Д., Акберова Э. М., Небавская К. А. // Журнал физической химии, 2014, т. 88, № 8, с. 1114-1120.

21. Васильева В. И., Акберова Э. М., Шапошник В. А., Малыхин М. Д. // Электрохимия, 2014, т. 50, № 8, с. 875-883.

22. Васильева В. И., Акберова Э. М., Демина О. А., Кононенко Н. А., Малыхин М. Д. // Электрохимия, 2015, т. 51, № 7, с. 711-721.

23. Акберова Э. М., Васильева В. И., Малыхин М. Д. // Конденсированные среды и межфазные границы , 2015, т. 17, № 3, с. 273-280.

24. Shaposhnik V.A., Vasil’eva V. I., Grigorchuk O. V. // Advances in Colloid and Interface Science, 2008, vol. 139, pp. 74-82.

25. Vasil'eva V., Zhiltsova A., Shaposhnik V., Zabolotsky V., Lebedev K., Malykhin M. “Ion Transport in Organic and Inorganic Membranes”, Proceedings of Intern. Conf., 28 May - 2 June, 2012, Krasnodar, 2012, pp. 233-235.

26. Васильева В. И., Жильцова А. В., Малыхин М. Д., Заболоцкий В. И., Лебедев К. А., Чермит Р. Х., Шарафан М. В. // Электрохимия, 2014, т. 50, № 2, с. 134 143.

27. Сирота Е. А., Кранина Н. А., Васильева В. И., Малыхин М. Д., Селеменев В. Ф. // Вестник Воронежского государственного университета. Серия: Химия. Биология. Фармация, 2011, № 2, с. 53-59.

28. Васильева В. И., Акберова Э. М., Заболоцкий В. И. // Электрохимия, 2017, т. 53, № 4, с. 452465.

\title{
DIFFUSION BOUNDARY LAYERS IN SOLUTIONS AT THE INTERPHASE WITH THE SULFOCATION-EXCHANGE MEMBRANE AFTER TEMPERATURE MODIFICATION
}

\author{
(c) 2017 E. M. Akberova \\ Voronezh State University, 1 Universitetskaya sq., 394018 Voronezh, Russia \\ e-mail:elmara_09@inbox.ru
}

Received 19.06.2017

\begin{abstract}
The use of the laser interferometry method allows measuring local concentrations and visualizing the process of formation and development of diffusion layers in solutions near the surface of the ion-exchange membrane. The prolonged exposure of the current and elevated temperatures to heterogeneous ion-exchange membranes leads to irreversible changes in the structure, which are interrelated with transport properties. Therefore, the purpose of this work is to measure the concentration profiles and parameters of the diffusion boundary layers in the solution at the interphase with heterogeneous sulfocation-exchange membranes after temperature effect by laser interferometry.

A commercial heterogeneous MK-40 membrane was chosen as the study object, it consisted of the KU-2 sulfocation-exchanger, polyethylene, and caprone. After chemical conditioning, the membrane
\end{abstract}


samples were thermostated at $100{ }^{\circ} \mathrm{C}$ in water for $50 \mathrm{~h}$. The experiments were performed in a sevencompartment electrodialysis cell with alternating cation-exchange and anion-exchange membranes at stable concentration-temperature stratification of the electrodialyzer in a gravitational field. To visualize the transport processes at the membrane-solution boundary, a Mach-Zehnder setup was used.

The concentration profiles and the dimensions of the diffusion boundary layers in the solution at the interphase with the MK-40 sulfocation-exchange membrane after chemical conditioning and temperature influence were determined using laser interferometry. It is shown that at current densities, exceeding the limiting diffusion values, the concentration profiles are transformed from stationary to nonstationary due to electroconvective instability arising in the solution at the interphase. It is established that at the overlimiting current densities, changes in the surface morphology and microstructure of membranes after heating determine the intensity of the electroconvective mixing of the solution at the interphase and the parameters of the diffusion layers. After the temperature modification, it was established that there was more intense electroconvective instability and a decrease in the thickness and then the destruction of the Nernst diffusion layer, with smaller degree of membrane polarization than for the conditioned membrane.

Keywords: heterogeneous sulfocation-exchange membrane, concentration profile, diffusion boundary layer, temperature modification.

\section{ACKNOWLEDGMENTS}

This work was financially supported by RFBR grant (project No 16-38-00572 mol_a).

\section{REFERENCES}

1. Shaposhnik V. A., Vasil'eva V. I., Reshetnikova E. V. Russ. J. Electrochem., 2000, vol. 36, pp. 773-777. DOI: 10.1007/BF02757679

2. Vasil'eva V. I., Shaposhnik V. A., Zabolotskii V. I., Lebedev K. A., Petrunya I. P. Sorption and Chromatographic Processes, 2005, vol. 5, no. 4, pp. 545-560. Available at: http://www.sorpchrom.vsu.ru/articles/abs-20050411. pdf (in Russian)

3. Vasil'eva V. I., Shaposhnik V. A., Grigorchuk O. V., Petrunya I. P. Desalination, 2006, vol. 192, no. 1-3, pp. 408-414. DOI: 10.1016/j.desal.2005.06.055

4. Shaposhnik V. A., Vasil'eva V. I., Grigorchuk O. V. Russ. J. Electrochem., 2006, vol. 42, no. 11, pp. 1202-1207. DOI: $10.1134 / \mathrm{S} 1023193506110061$

5. Vasil'eva V. I., Grigorchuk O. V., Botova T. S., Zabolotskii V. I., Lebedev K. A. Sorption and Chromatographic Processes, 2008, vol. 8, no. 3, pp. 359-379. Available at: http://www.sorpchrom.vsu.ru/articles/20080301.pdf (in Russian)

6. Nikonenko V. V., Vasil'eva V. I., Akberova E. M., Uzdenova A. M., Urtenov M. K., Kovalenko A.V., Pismenskaya N.P., Mareev S.A., Pourcelly G. Advances in Colloid and Interface Science, 2016, vol. 235, pp. 233-246. DOI: 10.1016/j.cis.2016.06.014

7. Rubinstein I., Zaltzman B. Phys. Rev. E, 2000, vol. 62, pp. 2238-2251. DOI: 10.1103/PhysRevE.62.2238

8. Pivovarov N. Ya., Greben’ V. P., Kustov V. N., Golikov A. P., Rodzik I. G. Russ. J. Electrochem., 2001, vol. 37, no. 8, pp. 941-952.DOI: 10.1023/A:1016782919030

9. Pis'menskaya N. D., Nikonenko V. V., Mel'nik N. A., Pourcelli G., Larchet G. Russ. J. Electrochem, 2012, vol. 48, pp. 610-628. DOI: 10.1134/S1023193512060092
10. Zabolotskii V. I., NikonenkoV. V., Urtenov M. Kh., Lebedev K. A., Bugakov V. V. Russ. J. Electrochem., 2012, vol. 48, p. 692-703.DOI:10.1134/S102319351206016X

11. Vasil'eva V. I., Zhiltsova A. V., Akberova E. M., Fataeva A. I. Condensed Matter and Interphases, 2014, vol. 16, no. 3, pp. 257-261. Available at: http://www.kcmf. vsu.ru/resources/t_16_3_2014_003.pdf (in Russian)

12. Knyaginicheva E. V., Belashova E. D., Sarapulova V. V., Pismenskaya N. D. Condensed Matter and Interphases, 2014, vol. 16, no. 3, pp. 282-287. Available at: http://www.kcmf.vsu.ru/resources/t_16_3_2014_007.pdf (in Russian)

13. Saldadze G. K. Ion-selective Membranes and Electromembrane Processes. Moscow, NIITEKChim. Publ., 1986, pp. 18-24. (in Russian)

14. Berezina N. P., Ivina O. P., Rubinina D. V. Diagnosis of Ion-Exchange Membranes after Real Electrodialysis. Krasnodar, Kuban. Gos. Univ. Press., 1990, 11 p. (in Russian)

15. Saldadze K. M., Klimova S. V., Titova N. A., Bazikova G. D. Ion-Exchange Membranes inElectrodialysis. Leningrad, Chemistry Publ., 1970, pp. 65-75. (in Russian)

16. Vasil'eva V. I., Bitjutskaya L. A., Zaychenko N. A., Grechkina M. V., Botova T. S., Agapov B. L. Sorption and Chromatographic Processes, 2008, vol. 8, no. 2, pp. 260271. Available at: http://www.sorpchrom.vsu.ru/articles/20080210.pdf (in Russian)

17. Dammak L., Larchet C., Grande D. Separation and Purification Technology, 2009, vol. 69, no. 1, pp. 43-47. DOI:10.1016/j.seppur.2009.06.016

18. Pis'menskaya N. D., Nikonenko V. V., Mel’nik N. A., Shevtsova K. A., Dammak L., Larchet C. Petroleum Chemistry, 2011, vol. 51, iss. 8, pp. 610-619. DOI: 10.1134/ S0965544111080081.

19. Vasil'eva V. I., Akberova E. M., Zhiltsova A. V., Chernykh E. I., Sirota E. A., Agapov B. L. J. Surface Inves- 


\section{Э. М. АКБЕРОВА}

tigation. Xray, Synchrotron and Neutron Techniques, 2013, vol. 7, no. 5, pp. 833-840. DOI:10.1134/S10274510130 50194

20. Vasil'eva V. I., Pismenskaya N. D., Akberova E. M., Nebavskaya K. A. Russ. J. Phys. Chem. A, 2014, vol. 88, no. 8, pp. 1293-1299. DOI:10.1134/S0036024414080317

21. Vasil’eva V. I., Akberova E. M., Shaposhnik V. A., Malykhin M. D. Russ. J. Electrochem, 2014, vol. 50, pp. 789-797. DOI:10.1134/S102319351408014X

22. Vasil'eva V. I., Akberova E. M., Demina O. A., Kononenko N. A., Malykhin M. D. Russ. J. Electrochem, 2015, vol. 51, pp. 627-637. DOI: 10.1134/S1023193515 070101

23. Akberova E. M., Vasil'eva V. I., Malykhin M. D. Condensed Matter and Interphases, 2015, vol. 17, no. 3, pp. 273-280. Available at: http://www.kcmf.vsu.ru/article. php?l=ru\&aid=686 (in Russian)

24. Shaposhnik V. A., Vasil'eva V. I., Grigorchuk O. V. Advances in Colloid and Interface Science, 2008, vol. 139, pp. 74-82. DOI:10.1016/j.cis.2008.01.008
25. Vasil'eva V., Zhiltsova A., Shaposhnik V., Zabolotsky V., Lebedev K., Malykhin M. "Ion Transport in Organic and Inorganic Membranes”, Proceedings of Intern. Conf., 28 May - 2 June, 2012, Krasnodar, 2012, pp. 233235.

26. Vasil'eva V. I., Zhil’tsova A. V., Malykhin M. D., Zabolotskii V. I., Lebedev K. A., Chermit R. Kh., Sharafan M. V. Russ. J. Electrochem., 2014, vol. 50, no. 2, pp. 120-128. DOI: 10.1134/S1023193514020062

27. Sirota E. A., Kranina N. A., Vasil'eva V. I., Malykhin M. D., Selemenev V. F. Proceedings of Voronezh State University. Series: Chemistry. Biology. Pharmacy, 2011, no. 2, pp. 53-59. Available at: http://www.vestnik.vsu.ru/ program/view/view.asp?sec=chembio\&year=2011\&num= 02\&f_name=2011-02-08 (in Russian)

28. Vasil'eva V. I., Akberova E. M., Zabolotskii V. I. Russ. J. Electrochem., 2017, vol. 53, no. 4, pp. 398-410. DOI: $10.1134 /$ S1023193517040127
Акберова Эльмара Маликовна - к. х. н., ведущий инженер кафедры аналитической химии, Воронежский государственный университет; e-mail: elmara_09@inbox.ru.
Akberova Elmara M. - Cand. Sci. (Chem.), Leading Engineer of the Analytical Chemistry Department, Voronezh State University; e-mail: elmara_09@inbox.ru 